\title{
Importancia de estimular las inteligencias múltiples en educación inicial. Habilidades y destrezas
}

\section{Importance of stimulating multiple intelligences in initial education. skills and abilities}

Tannia Alexandra Casanova Zamora ${ }^{1}$

\section{Eliana Vanessa Arias Calderón²}

Jakelin Paulina Trávez Angueta ${ }^{3}$

Angela Vanessa Ortiz Lucero ${ }^{4}$

Universidad Nacional de Chimborazo (UNACH)

Riobamba - Ecuador

1 UNIVERSIDAD NACIONAL DE CHIMBORAZO (UNACH), ECUADOR. Facultad de Ciencias de la Educación, Humanas y Tecnologías - Carrera de Educación Inicial. Grupo Neuropsicopedagogia. Mg. Tannia Alexandra Casanova Zamora. Licenciada en Educación Parvularia e Inicial, Magister en Desarrollo de la Inteligencia y Educación, Doctorante en Pedagogía Universidad de la Habana Cuba. Correo tcasanova@unach.edu.ec https://orcid.org/0000-0002-6005-2414

2 UNIVERSIDAD NACIONAL DE CHIMBORAZO (UNACH), ECUADOR. Facultad de Ciencias de la Educación, Humanas y Tecnologías - Carrera de Educación Inicial. Eliana Vanessa Arias Calderón Estudiante de Séptimo Semestre de la Carrera de Educación Inicial. Capacitación en: "Educación con énfasis en la primera infancia" por 40 horas, "Il Encuentro Internacional de Literatura Infantil y Juvenil" por 40 horas. Correo eliana.arias@unach.edu.ec https://orcid.org/0000-0002-0078-6926 3 UNIVERSIDAD NACIONAL DE CHIMBORAZO (UNACH), ECUADOR. Facultad de Ciencias de la Educación, Humanas y Tecnologías - Carrera de Educación Inicial. Jakelin Paulina Trávez Angueta. Estudiante de séptimo semestre de la carrera de educación inicial. Capacitación en: "Las cargas eléctricas el cerebro, la sinapsis, y sus efectos en la conducta humana frente a la neurociencia del siglo XXI" por 120 horas, "II Encuentro Internacional de Literatura Infantil y Juvenil" por 40 horas. Correo jakelin.travez@unach.edu.ec https://orcid.org/0000-0003-4553-2003

4 UNIVERSIDAD NACIONAL DE CHIMBORAZO (UNACH), ECUADOR. Facultad de Ciencias de la Educación, Humanas y Tecnologías - Carrera de Educación Inicial. Angela Vanessa Ortiz Lucero. Estudiante de Séptimo Semestre de la Carrera de Educación Inicial. Capacitación en: "Educación con énfasis en la primera infancia" por 40 horas. Correo angela.ortiz@ unach.edu.ec https://orcid.org/0000-0002-1665-3933 


\section{RESUMEN}

La educación infantil ha evolucionado y junto con esta se espera que también devengan las metodologías de enseñanza. Dejamos atrás la educación tradicional que ha limitado los procesos de enseñanza - aprendizaje, forzando a los infantes a adquirir conocimientos únicamente de manera unidireccional siendo el docente quien puede aportar conocimiento. Con este tipo de educación limitamos las habilidades y capacidades de los niños, cuando en realidad podríamos estimular las Inteligencias Múltiples al punto de crear seres humanos competentes listos para desenvolverse e interactuar dentro de cualquier entorno convirtiéndose en seres sociales empáticos, que tengan un sentido democrático, crítico y autónomo. En el estudio que hemos realizado podemos determinar que dentro del grupo que fue analizado la mayoría de ellos mostraban una inclinación superior por la Inteligencia Visual y una inclinación menor en la Inteligencia Interpersonal. Basándonos en los resultados obtenidos los docentes tendremos la posibilidad de usar estos datos para plantear nuevas estrategias metodológicas que hagan un aporte significativo para estimular las Inteligencias Múltiples a través de actividades apropiadas a cada etapa del desarrollo infantil y para que cada una de estas sean estimuladas con la finalidad de darle al niño la posibilidad de potencializar su inteligencia.

\section{PALABRAS CLAVE}

Aprendizaje, capacidades, habilidades, inteligencia múltiples, metodologías

\section{ABSTRACT}

Early childhood education has evolved; therefore teaching methodologies must also do so. We leave behind traditional education that has limited the teaching - learning processes, forcing infants to acquire knowledge only in an unidirectional way where the teacher is the only one who provides knowledge. With this type of education we limit the abilities and capabilities of children, when in reality we could stimulate multiple Intelligences to the point of creating competent human beings ready to function and interact within any environment, thus becoming empathic social beings that have a democratic sense, are critical and autonomous. In the study that we have carried out, we can determine that within the group that was analyzed, most of them showed a higher inclination for visual intelligence and a lower inclination for interpersonal intelligence. Based on the results obtained, the teachers will have the possibility of using this data to propose new methodological strategies that make a significant contribution to stimulate Multiple Intelligences.

\section{KEY WORDS}

Learning, capabilities, abilities, multiple intelligence, methodologies

\section{INTRODUCCIÓN}

A lo largo de nuestra vida estudiantil hemos sido categorizados como muy, medianamente o poco inteligentes con base a una calificación obtenida en las diversas asignaturas estudiadas, pero ¿Es realmente una calificación lo que define el nivel de inteligencia que poseemos?, la respuesta a esto es no, una calificación no puede definir el nivel de inteligencia que posee cada persona y menos aun cuando se realiza una prueba para evaluar una única parte de nuestro conocimiento.

Howard Gardner propuso la teoría de la Inteligencias múltiple (I.M) en el año 1983 en su libro titulado Estructuras de la mente en el cual define a la inteligencia como "la capacidad de resolver problemas $o$ de crear productos que sean valiosos en uno o más ambientes culturales" (Gardner, 2016)(p.4) 
Gardner se resistía a aceptar que existiera un solo tipo de inteligencia, pues considera que la mente del ser humano es tan compleja que resultaría imposible encasillarla en un solo tipo. Creer que la inteligencia es un recurso que puede medirse numéricamente implicaría que todos somos iguales que tenemos los mismos gustos, inclusive que crecimos y nos formamos en un ambiente idéntico, lo cual es algo irreal. Por tanto, estamos ignorando la diversidad que nos hacen ser las personas que somos, todos distintos e igual de valiosos.

Gardner desestimó la afirmación de que la inteligencia es innata en la persona. A decir de (Guzmán \& Castro, 2005) la inteligencia no es una característica innata, sino que se desarrolla como resultado del aprendizaje, del entrenamiento y la práctica. Así pues, ahora sabemos que el desarrollo y formación de la persona dependerá de la estimulación, la educación puede modificar las inteligencias ya que contamos con la posibilidad de ejercitarlas.

(Antunes, 2006) Menciona que el niño necesita la escolaridad para "aprender a aprender", para desarrollar sus habilidades y estimular sus inteligencias, es así que el docente se convierte en guía estimulador de los niños.

Antes de la escolarización el niño ya empieza a desarrollar sus inteligencias, pues empieza trabajando con el hemisferio derecho dando mayor énfasis que al izquierdo, pues en él se encuentran las funciones más blandas como la creatividad, la intuición, la espiritualidad, la sensibilidad, etc.

En el contexto educativo el docente juega un papel fundamental en el desarrollo intelectual del niño, aunque si bien el sistema educativo actual se enfoca en desarrollar el lado izquierdo con funciones más duras, como son, el razonamiento, la memoria, el pensamiento, etc. la propuesta es estimular ambos hemisferios, es decir desarrollar lo más posible las inteligencias.

\section{LA ESCUELA TRADICIONAL Y LAS INTELIGENCIAS MÚLTIPLES}

La escuela tradicional aparece en el siglo XVII en Europa y con el surgimiento de la burguesía, esta se vuelve una de las expresiones para dar inicio a la modernidad, las tendencias pedagógicas que lo caracterizan son propias del siglo XIX, las mismas que han tenido una influencia significativa en el terreno educativo en el siglo $X X$.

El hombre ha elaborado propuestas acerca de la educación, sus protagonistas, el proceso de enseñanza - aprendizaje, sus finalidades y el modo de realización, su concepción descansa en el criterio de que es la escuela la institución social encargada de la educación pública masiva y también valorada como fuente fundamental de la información, la cual tiene la misión de preparar intelectual y moralmente a los estudiantes. (Arcken, 2012)

En la escuela tradicional el profesor asume el poder y la autoridad como transmisor esencial de conocimiento, el cual exige disciplina y obediencia, tomando así una imagen de imposición, es decir, es el centro del proceso de enseñanza, transmitiendo información de una forma expositiva con procedimientos siempre verbalistas, dando poco margen para que el estudiante trabaje y establezca sus habilidades, dando lugar a una personalidad pasiva y dependiente, lo que hace que se aprecie más al profesor como sujeto del proceso de enseñanza. (CEPES, 2000)

El sistema educativo debe enfocarse en brindar mayor atención a la educación del niño, pues se le considera como una persona distinta a la adulta, por lo tanto, se debe prestar atención al proceso evolutivo, estudiando cada una de las etapas del desarrollo, a través de estas necesidades surge el activismo, dejándose de ver al niño como ser pasivo, buscando cuáles 
son las necesidades del mismo, de modo que se ajuste al proceso educativo.

La escuela debe formar jóvenes listos para vivir dentro de su medio social, teniendo un sentido democrático, propiciando la colaboración y ayuda mutua, por lo tanto, la escuela debe ser una comunidad en miniatura, el papel del docente debe ser proporcionar el medio "que estimule" la respuesta necesaria y dirija el aprendizaje. (Castro, 1939)

Es necesario Identificar las fortalezas de los niños en lugar de las carencias, aunque por muy fácil que parezca plantearlo muchas de las veces hemos hecho lo contrario y eso hasta el día de hoy, el sistema educativo debería permitir una planificación educativa adecuada, la misma que se pueda adaptar a las necesidades de cada estudiante.

Es evidente que en la mayoría de escuelas se adaptan a currículos uniformes, ocasionando que estudien las mismas asignaturas presentadas y a más de ello estudiarlas de idéntica forma, esto quiere decir que no se hace el mayor intento por buscar estrategias metodológicas para estimular las diferentes inteligencias que poseen los estudiantes y así adquirir conocimientos, cabe recalcar que todas las inteligencias múltiples son importantes, de hecho, la educación debería considerar a todas por igual, dándoles el mismo interés y sobre todo trabajando de forma equitativa con los estudiantes.

Los nuevos tiempos requieren nuevas estrategias educativas y lo que está claro es que una escuela que sea útil ha de considerar el aprendizaje para la vida, es necesario valorar las diferentes capacidades que tienes los estudiantes para adquirir un nuevo conocimientos, pues se sabe que es un poco difícil descifrar sobre como aprende el estudiante y cuáles son sus fortalezas e intereses, por lo tanto la escuela debe buscar estrategias para así poder utilizar todos los recursos pedagógicos disponibles con el objetivo de que los estudiantes adquieran los conocimientos necesarios, en ello juega un papel fundamental el maestro, dejando de ser un transmisor de conocimientos y convirtiéndose en un guía que acompaña en el procesos de aprendizaje real del estudiante permitiéndole adquirir las competencias requeridas en pleno siglo XXI. (Guillén, 2013)

Es necesario que la escuela se enfoque en trabajar en conjunto con docentes y padres de familia, cuyo objetivo sea el mismo, identificar y buscar estrategias metodológicas que se adapten a las necesidades diferentes de cada estudiante, por lo tanto se ha buscado la manera de facilitar estimular y trabajar por igual los tipos de inteligencias de cada estudiante, por ese motivo Gardner propone que los profesores se valgan de una metodología amplia, que incluyan ejercicios y actividades que impliquen los ocho tipos de inteligencia y no solo dos de ellas. (ACRBIO, 2015)

\section{EL ESTÍMULO DE LAS INTELIGENCIAS MÚLTIPLES EN LA PRIMERA INFANCIA}

En la primera infancia los niños necesitan nutrición, protección y estimulación, que son factores esenciales para conseguir mejorar el desarrollo intelectual, emocional, social, cultural y corporal de un niño. La etapa comprendida desde los 0 a 3 años, es una etapa donde se produce un desarrollo acelerado e integral siempre y cuando se involucre a todas las inteligencias que poseemos.

Los progresos recientes en el campo de la neurociencia según nos indica (Céspedes, 2019) podemos conocer que hasta los 5 años la corteza dispone de 300 billones de neuronas, a los 7 años, se dispone de 200 billones y de los doce años en adelante tan solo 100 billones de neuronas para conectarse entre sí. Estos datos nos dan la pauta para intentar estimular cientos 
de características y otorgarles a nuestros niños herramientas para la vida. Amanda Céspedes, habla acerca de los diversos componentes de la inteligencia, enfocándose en una facultad innata de nuestro cerebro llamada plasticidad. Hablando en términos científicos la plasticidad es la capacidad que posee nuestro cerebro para adaptarse y modificar la información adquirida con anterioridad para dar una respuesta a los diferentes estímulos.

Generalmente los padres demandan a sus hijos que se destaquen en el área académica dándole una importancia desmedida a las calificaciones, pasando por alto que estas mismas si bien pueden otorgar un estatus, no garantizan el éxito profesional ni personal. Pues no les ha dado la oportunidad de desenvolverse libremente en otras áreas.

Cada persona tiene un perfil de inteligencia debido a que unas se destacan más que otras, lo cual no quiere decir que no las poseamos, simplemente que tenemos menor inclinación hacia ellas. Por medio de la observación podemos distinguir cuales son aquellos aspectos que predominan y empezar a trabajarlos, el objetivo es crear dentro del hogar y la escuela espacios de recreación en los que los niños puedan estimular los diferentes tipos de inteligencia, sin olvidar celebrar su esfuerzo en cada intento.

Para alcanzar un desarrollo completo se requiere de un esfuerzo de los niños, docentes y padres de familia quienes deben involucrarse en el proceso desde una edad temprana, los docentes son facilitadores de información como teorías, metodologías y técnicas de enseñanza. La estimulación de las inteligencias múltiples ayudará a descubrir las actividades de su interés ya sean deportes, música, libros y en un futuro se podrán definir por una profesión que realmente les apasione. Muchas personas realmente no lo que les gusta, porque recibieron una educación muy rígida.

En la etapa de la primera infancia cada niño podrá potenciar este conjunto de, de manera que se pueda aprovechar la diversidad de cada estudiante para incluir actividades que contribuyan al fortalecimiento de cada niño, acercándolos al conocimiento desde sus habilidades y destrezas más notorias, para lograr su óptimo desarrollo.

El médico estadunidense Glenn Doman diseñó programas llamados bits en los cuales trataba de agrupar estímulos de las inteligencias múltiples de manera que se incremente las posibilidades intelectuales, con este método se logra captar la atención y que se crean innumerables conexiones neuronales y se trabaja la memoria. Por ejemplo: los nombres de los animales son enseñados a los niños junto una imagen que los represente, estas imágenes deben ser de los animales reales para que puedan identificarlos claramente y al repetirlas o verlas varias veces durante un tiempo; llegaran a reconocerlos sin problemas. Es importante respetar el ritmo de aprendizaje y realizar las actividades con calma. Los bits de información deberán ser simples para no distraer al niño del tema, novedosos para lograr llamar su interés y complete la actividad y adecuados a la edad y nivel de desarrollo para evitar frustrar al estudiante en caso de que no logre completar la tarea. Los periodos de tiempo que se trabaja para aplicar este programa deben ser cortos, para no cansar o aburrir al niño. (Escalonilla, 2020)

El objetivo del Doman es no saturar al niño con conocimiento académico, sino preparar su cerebro, estimular su plasticidad cerebral, desarrollar habilidades y potenciar su capacidad de aprendizaje. Esta escuela tan estricta le impide 
al niño equivocarse, lo que desafortunadamente crea inseguridad que no le dejará experimentar cosas nuevas, disfrutar de su entorno y tampoco valorar sus logros.

\section{LAS INTELIGENCIAS MÚLTIPLES EN EL APRENDIZAJE DE NIÑOS DE EDUCACIÓN INICIAL}

Al hablar de inteligencia múltiples tratamos las diferencias que hay entre los individuos, el modo de actuar, intereses, capacidades, etc. con ello llegamos al punto que no todos aprendemos de la misma manera. Esto debería ser la base de la educación, las unidades educativas deberían fijar al alumno como centro del proceso de enseñanza aprendizaje.

Los salones de clase están conformados por una gran diversidad de estudiante, todos ellos con diferentes contextos familiares, sociales, económicos, muchos de ellos desmotivados, otros, más enfocados en el auge de la tecnología e incluso algunos incapaces de concentrar su atención en el aula, este panorama educativo nos obliga a incorporar metodologías más atractivas, motivadoras, activas, que despierten el niño el interés y la curiosidad por descubrir un nuevo conocimiento.

Dentro de las inteligencias múltiples como método de enseñanza encontramos las propuestas conductistas de Skinner, sin dejar de lado las ideas constructivistas de Piaget, integrando el aprendizaje autónomo y activo propuesto por Montessori, también involucrando el aprendizaje por descubrimiento de Brunner, generando el los niños aprendizajes significativos como lo manifiesta Ausubel, involucrando todo ello en la dimensión social propuesta por Vygotsky. Como podemos ver la teoría de inteligencias múltiples nos es una teoría aislada, sino aquella que involucra muchas otras promoviendo un mejor desenvolvimiento del niño en el salón de clases $y$ en el medio que lo rodea.
Gardner tenía la concepción que la mente es capaz de tratar distintos contenidos de distintas maneras mostrando así distintas inteligencias y no solo una única inteligencia flexible, proponiendo a las I.M como una actitud hacia el aprendizaje o como una meta-modelo educacional. De este modo Armstrong citado por (Ordoñez-Islas, 2006), menciona que las I.M ofrece a los educadores una oportunidad muy amplia para adaptar de manera creativa sus principios fundamentales a cualquier cantidad de contextos educacionales (p.18)

Es importante cuestionarnos si lo que aprenden los niños día a día en el salón de clases les permite responder y enfrentar los retos que viven en sus vidas, pensemos si en realidad las actividades que realizan los niños están desarrollando su inteligencia. (González, 2014), manifiesta que la escuelas requiere incorporar metodologías más activas como el aprendizaje cooperativo, las rutinas y destrezas del pensamiento, el trabajo por proyectos, el aprendizaje reflexivo, la enseñanza basada en la resolución de problemas o el aprendizajeservicio. (p.5)

Dentro de las ocho inteligencias que Gardner propuso se encuentran tanto las tomadas como tradicionales, como algunas a las que únicamente se les denominaba talentos, estas son: lingüística, lógico-matemática, viso-espacial, corporal-cinestésica, musical, naturalista, interpersonal, intrapersonal. Todas estas inteligencias con capaces de desarrollarse en el salón de clases, ahora estableceremos algunas pautas para poder desarrollarlas $y$ promoverlas.

La inteligencia lingüística se la ha establecido como la capacidad de manejar el lenguaje de forma efectiva, en ella debemos desarrollar las capacidades de expresión y comunicación con actividades de lectura, escritura y expresión oral. Podemos promoverla con el uso de historias 
y relatos, jugando con palabras, adivinanzas, rimas, trabalenguas.

La inteligencia lógico-matemática en ella se establece una serie de habilidades como razonar, calcular, cuantificar, resolver operaciones matemáticas, etc. En niños pequeños debemos potenciar habilidades de clasificación, la curiosidad, el análisis, las relaciones lógicas (objeto-acción), la resolución de problemas.

La inteligencia viso-espacial es la capacidad de distinguir visual y espacialmente todo lo que nos rodea decodificando información gráfica. En ella debemos potenciar la observación, la recreación de imágenes y la ubicación en tiempo y espacio.

La inteligencia corporal-cinestésica es la capacidad de expresar ideas y sentimientos controlando los movimientos del cuerpo y manejando objetos con destreza. Los niños que destacan en esta inteligencia disfrutan corriendo, saltando, bailando, actuando. La mejor manera de fortalecerla es realizando juegos al aire libre en donde los niños puedan moverse con libertad.

La inteligencia musical es la percepción, discriminación y transformación de formas musicales, aquí potenciamos el canto, la entonación, la apreciación melódica, actividades como tararear y silbar.

La inteligencia naturalista conocida como la habilidad de conocer en mundo natural, podemos utilizar técnicas de observación, comprobación, experimentación y utilización objetos del ambiente.

La inteligencia interpersonal es la capacidad de conocer a los demás, reconocer emociones, motivaciones, intenciones y de relacionarse de manera eficaz, en ella debemos motivar la interacción, el liderazgo, la organización, el trabajo cooperativo, la mediación, la empatía, la fluidez.
La inteligencia intrapersonal supone la capacidad de conocerse a uno mismo, el acceso a los propios sentimientos y emociones, aquí es fundamental desarrolla la autoestima, autoconfianza, auto-comprensión, la reflexión y la regulación de comportamiento.

Todas y cada una de esta inteligencias son esenciales en el desarrollo de los niños y ellos tienen la capacidad para activarlas, ciertamente como Gardner lo manifiesta no todos vamos a llegar a poténcialas igual pero el objetivo es combinar todas las capacidades, fortalezas y talentos para la resolución de retos cotidianos.

\section{HABILIDADES Y DESTREZAS ADQUIRIDAS CON LA ESTIMULACIÓN DE LAS INTELIGENCIAS MÚLTIPLES}

Cuando Gardner formuló la teoría de inteligencias múltiples, esta tenía como horizonte la enseñanza centrada en el alumno, el desarrollo de habilidades, el compromiso con el entendimiento óptimo y el desarrollo del perfil cognitivo de cada estudiante. (Sánchez, 2015), afirma que cada una de I.M mantiene elementos que le son propios para atender la diversidad de los alumnos y satisfacer sus tendencias de enseñanza - aprendizaje. Dándonos la oportunidad como educadores de aclarar desde qué inteligencia cada niño tiene más posibilidades de aprender. (p.6)

Según (Ramírez, 2013). En la actualidad se hace caso omiso a los dones y habilidades de los niños y niñas, focalizando la atención sólo en sus debilidades y la manera de cómo remediarlas, perdiendo ese inmenso poder del cerebro que está en espera de ser potencializado. (p.62)

A lo largo de la historia se ha establecido diversas definiciones de habilidad, a esta se le da varias interpretaciones dependiendo a 
que rama de la ciencia está enfocado el autor, esta puede ser la pedagogía o la psicología. (Sixto \& Márquez, 2017), citando al "Campo de Opiniones" confeccionado por Spirin LF, manifiestas definiciones como:

- Grusdev N. (1949): "La habilidad es el conjunto de diferentes hábitos como casos particulares de sus funciones".

- Milerian E.A. (1958): "La habilidad como conocimiento activo. Habilidad como la capacidad, basada en los conocimientos y hábitos, de alcanzar exitosamente los objetivos conscientemente planteados de la actividad en condiciones variables de su realización (...). Cualquier habilidad está indisolublemente ligada con el razonamiento creativo del hombre".

Con estas definiciones podemos decir que la habilidad es la capacidad de realizar cierta actividad ya sea cognitiva, física o social, que también depende de los hábitos y la experiencia previa de la persona.

A continuación se presenta el cuadro 1 en el que se establece las habilidades que se desarrollan en cada inteligencia propuesta por Gardner y cómo podemos identificar la presencia de estas en los niños.

\section{Cuadro 1}

Inteligencias múltiple. Habilidades

\begin{tabular}{|c|c|c|}
\hline INTELIGENCIA & HABILIDAD & AFINIDAD POR \\
\hline LINGÜÍSTICA & $\begin{array}{l}\text { Lectura, escritura, narración de } \\
\text { historias, memorización de fechas, } \\
\text { piensa en palabras. }\end{array}$ & $\begin{array}{l}\text { Leer, escribir, contar cuentos, } \\
\text { hablar, memorizar, hacer } \\
\text { puzles. }\end{array}$ \\
\hline $\begin{array}{c}\text { LÓGICA - } \\
\text { MATEMÁTICA }\end{array}$ & $\begin{array}{l}\text { Matemáticas, razonamiento, lógica, } \\
\text { resolución de problemas, pautas. }\end{array}$ & \begin{tabular}{|l} 
Resolver $\quad$ problemas, \\
cuestionar, trabajar con \\
números, experimentar. \\
\end{tabular} \\
\hline ESPACIAL & $\begin{array}{l}\text { Lectura de mapas, gráficos, dibujando, } \\
\text { laberintos, puzles, imaginando cosas, } \\
\text { visualizando. }\end{array}$ & $\begin{array}{l}\text { Diseñar, dibujar, construir, } \\
\text { crear, soñar despierto, mirar } \\
\text { dibujos. }\end{array}$ \\
\hline CINÉTICAC & $\begin{array}{l}\text { Atletismo, danza, arte dramático, } \\
\text { trabajos manuales, utilización de } \\
\text { herramientas. }\end{array}$ & $\begin{array}{l}\text { Moverse, tocar y hablar, } \\
\text { lenguaje corporal. }\end{array}$ \\
\hline MUSICAL & $\begin{array}{l}\text { Cantar, reconocer sonidos, recordar } \\
\text { melodías, ritmos. }\end{array}$ & $\begin{array}{l}\text { Tener amigos, hablar con la } \\
\text { gente, juntarse con gente. }\end{array}$ \\
\hline INTERPERSONAL & $\begin{array}{l}\text { Entendiendo a la gente, liderando, } \\
\text { organizando, comunicando, resolviendo } \\
\text { conflictos. }\end{array}$ & $\begin{array}{l}\text { Trabajar solo, reflexionar, } \\
\text { seguir sus intereses. }\end{array}$ \\
\hline INTRAPERSONAL & \begin{tabular}{|l|} 
Comprendiéndose a sí mismo, \\
reconociendo los puntos fuertes y las \\
debilidades, estableciendo objetivos.
\end{tabular} & $\begin{array}{l}\text { Tener amigos, hablar con la } \\
\text { gente, juntarse con gente. }\end{array}$ \\
\hline NATURALISTA & $\begin{array}{l}\text { Entendiendo la naturaleza, haciendo } \\
\text { distinciones, identificando la flora y la } \\
\text { fauna. }\end{array}$ & $\begin{array}{l}\text { Participar en la naturaleza, } \\
\text { hacer distinciones. }\end{array}$ \\
\hline
\end{tabular}


Fuente: García, M. T. (2009). La dimensión comunicativa de las inteligencias múltiple. CIC. Cuadernos de Información y Comunicación. Red de Revistas Científicas de América Latina, el Caribe, España y Portugal. Vol. 14, página 145

Como se menciona en la teoría de las inteligencias múltiples, el docente debe generar diversos estímulos, brindando abundantes y variadas experiencias tomando para ello diversos enfoques en los cuales se involucre el movimientos, la expresión, la visualización, la cooperación, la individualidad, el entorno natural, la música y las relaciones lógico matemáticas, propendiendo así la manera única que cada niño posee para llegar al conocimiento.

De acuerdo a (Ramírez, 2013). Una destreza es la expresión del 'saber hacer', que caracteriza el dominio de la acción. Las destrezas cognitivas son el andamiaje de todos los procesos que un estudiante aprende, porque priorizan el saber hacer de los alumnos y posibilitan movilizar hacia la práctica los contenidos, los procedimientos y la dimensión valorativa-actitudinal. (p.63)
(Pérez \& Murzi, 2012), establece que destreza significaba lo que se hacía correctamente con la mano derecha. Luego, pasó a significar las habilidades motoras requeridas para realizar ciertas actividades con precisión. (p.230)

En base a esto entendemos como destreza a la habilidad de hacer bien una cosa en específico, teniendo el conocimiento adecuado para aplicarlo con facilidad, agilidad y desenvolvimiento en el campo requerido.

Con la correcta estimulación de los centros educativos los niños de edad preescolar desarrollan un gran número de destrezas dentro de las diversas inteligencias como se muestra en el cuadro 2.

\section{Cuadro 2}

Inteligencias múltiples. Destrezas

\begin{tabular}{|c|l|}
\hline INTELIGENCIA & \multicolumn{1}{|c|}{ DESTREZAS } \\
\hline LINGÜÍSTICA & $\begin{array}{l}\text { Comprender, componer, escucha activa, escribir, leer, pronunciar, } \\
\text { definir, interpretar. }\end{array}$ \\
\hline $\begin{array}{c}\text { LÓGICA - } \\
\text { MATEMÁTICA }\end{array}$ & $\begin{array}{l}\text { Ordenar según características de tamaño, forma y color. } \\
\text { Comparar y diferenciar según altura, tamaño o género. } \\
\text { Diferencia entre lo real y lo abstracto. } \\
\text { Contar al menos hasta 20 y señalan y cuentan objetos de un grupo. }\end{array}$ \\
\hline ESPACIAL & $\begin{array}{l}\text { Entender que las imágenes y los símbolos representan cosas reales. } \\
\text { Explorar relaciones entre ideas imaginarias, usando palabras. } \\
\text { Comenzar a pensar en pasos lógicos. } \\
\text { Entender ideas abstractas como "más grande", "menos" "más tarde" } \\
\text { "hace tiempo" y "pronto". } \\
\text { Reconocer formas en el mundo real. }\end{array}$ \\
\hline
\end{tabular}




\begin{tabular}{|c|c|}
\hline CINÉTICA CORPORAL & $\begin{array}{l}\text { Se desarrolla todo lo referente a motricidad fina y gruesa. } \\
\text { Alternar sus pies al subir las escaleras. } \\
\text { Saltar con los dos pies. } \\
\text { Utilizar las manijas de las puertas } \\
\text { Controlar más fácilmente los movimientos de los músculos largos } \\
\text { Capacidad de detenerse, girar y rodear obstáculos mientras corren. } \\
\text { Rodar, hacer volteretas, saltar y trotar. } \\
\text { Lanzar y rebotar una pelota. } \\
\text { Saltar sobre objetos y trepar escaleras en el parque. } \\
\text { Pedalear y manejar un triciclo o una bicicleta. }\end{array}$ \\
\hline MUSICAL & $\begin{array}{l}\text { Desarrolla capacidad bio-psiquicas-culturales, ritmo y compás de la } \\
\text { música, balance, tono, conciencia corporal, coordinación-sensorio- } \\
\text { motoras-cognitivas. }\end{array}$ \\
\hline INTERPERSONAL & $\begin{array}{l}\text { Compartir, cooperar, ayudar y esperar su turno. } \\
\text { Disfrutar contando chistes y considerar divertidas otras cosas. } \\
\text { Jugar con otros niños y separarse más fácilmente de sus padres y } \\
\text { cuidadores. }\end{array}$ \\
\hline INTRAPERSONAL & $\begin{array}{l}\text { Comenzar a mostrar y expresar una amplia variedad de emociones. } \\
\text { Empezar a actuar de manera un poco autoritaria. } \\
\text { Tener amigos imaginarios y jugar los mismos juegos imaginarios. }\end{array}$ \\
\hline NATURALISTA & $\begin{array}{l}\text { Detecta, diferencia y categoriza todos aquellos aspectos relacionados } \\
\text { con la naturaleza ya sean animales, plantas, fenómenos climáticos, } \\
\text { etc. }\end{array}$ \\
\hline
\end{tabular}

Fuente: Elaboración Propia

Como se puede apreciar existe una gran cantidad de destrezas que pueden ser desarrollas en la etapa preescolar, enfocándonos en la aplicación de las inteligencias múltiples, también podemos observar que las destrezas van de la mano con las habilidades.

\section{APARTADO METODOLÓGICO}

Para el desarrollo de esta investigación se realizó un estudio no experimental con enfoque cualitativo, correspondiendo a una investigación aplicada de carácter social titulada "Las inteligencias múltiples en el desarrollo de las competencias básicas de los niños y niñas de los primeros años de educación básica”.

La muestra se conformó por 134 niños del primero año de educación general básica, de las Unidades Educativas Nazareno, Juan de Velazco, Capitán Edmundo Chiriboga, Amelia Gallegos Díaz y Liceo Nuevo Mundo en la ciudad de Riobamba Provincia de Chimborazo. A decir de (Hernández, Fernández \& Baptista, 
2003), la muestra consiste en la participación de personas con características comunes, en este caso cumplen el requerimiento de ser estudiante del primer años de educación general básica. En el cuadro 3 se establece la población por unidad educativa y género.

\section{Cuadro 3}

Instituciones Educativas. Población analizada

\begin{tabular}{|c|c|c|c|}
\hline UNIDAD EDUCATIVA & $\mathbf{N}^{\circ}$ DE MUJERES & $\mathbf{N}^{\circ}$ DE HOMBRES & TOTAL \\
\hline Juan de Velasco & 13 & 12 & 25 \\
\hline $\begin{array}{c}\text { Cristiana Nazareno } \\
\begin{array}{c}\text { Cap. Edmundo } \\
\text { Chiriboga }\end{array}\end{array}$ & 15 & 12 & 32 \\
\hline $\begin{array}{c}\text { Amelia Gallegos Díaz } \\
\text { Liceo Nuevo Mundo }\end{array}$ & 14 & 12 & 34 \\
\hline TOTAL & 64 & 15 & 17 \\
\hline
\end{tabular}

Fuente: Elaboración propia

Para este proyecto se ha priorizado la utilización de estudios planteados por Howard Gardner, quién propone aplicar un test, el mismo que constaba con 40 ítems, los mismo que ya fueron revisados y aplicados en proyectos anteriores, sin embargo estos ítems fueron modificados adaptándolos al contexto actual en el que se desenvolvían los niños.

\section{ANÁLISIS Y RESULTADOS}

Para llegar a estimular las Inteligencias Múltiples es necesario que evaluemos la presencia de las mismas dentro de los beneficiarios que conforman la población a la cual se ha aplicado el test de Howard Gardner. En la Cuadro 4 se ha condensado la información obtenida con la aplicación del instrumento de recolección de datos en las diferentes Unidades Educativas, la misma que se ha registrado de acuerdo con cada inteligencia que identifica Gardner. 


\section{Cuadro 4}

Inteligencias múltiples identificadas en los niños de 1er año de E.G.B.

\begin{tabular}{|l|c|c|}
\hline INTELIGENCIAS MULTIPLES & PARTICIPANTES & PORCENTAJES \\
\hline I. Verbal & 36 & $17 \%$ \\
\hline I. Lógica Matemática & 36 & $12 \%$ \\
\hline I. Visual Espacial & 42 & $20 \%$ \\
\hline I. Kinestésica - Corporal & 28 & $13 \%$ \\
\hline I. Musical - Rítmica & 24 & $11 \%$ \\
\hline I. Intrapersonal & 18 & $9 \%$ \\
\hline I. Interpersonal & 11 & $5 \%$ \\
\hline I. Naturalista & 26 & $12 \%$ \\
\hline TOTAL & $\mathbf{2 1 1}$ & $\mathbf{1 0 0} \%$ \\
\hline
\end{tabular}

Fuente: Elaboración propia

Gráfico 1

Presencia cuantitativa de I.M

INTELIGENCIASMULTIPLES

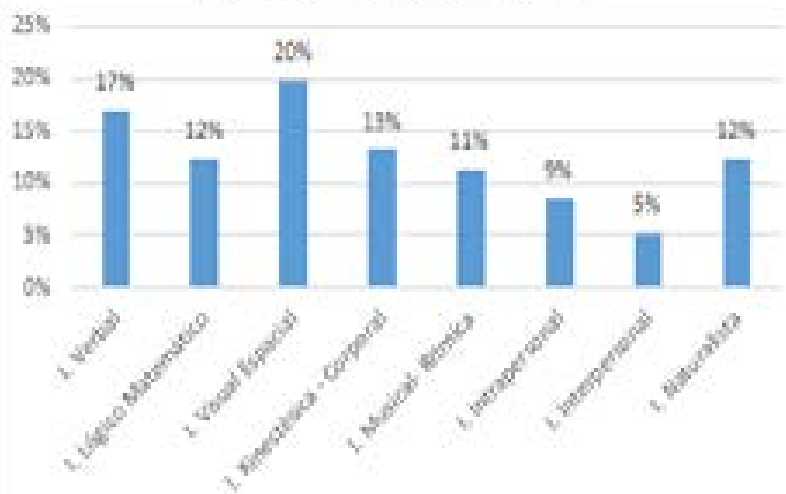

Gráfico 2

Presencia porcentual de I.M

INTELIGENCIAS MÚLTIPLES

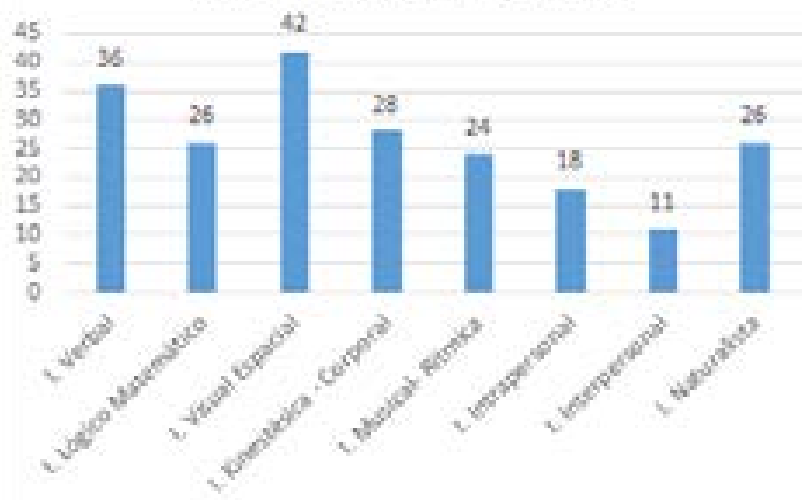

Fuente: Elaboración propia

Los resultados registrados son muy claros en cuanto a la presencia cuantitativa y porcentual de cada inteligencia sin embargo al comparar la población participante y los datos obtenidos, encontramos que, existen 211 resultados lo cual supera en 77 a la población que fue definida en un inicio, esto sucede debido a que algunos niños presentan 2 inteligencia como dominantes en lugar de una lo cual incrementa el número de inteligencias dominantes totales.
Podemos concluir que el mayor porcentaje se concentra en la Inteligencia Visual - Espacial con un $20 \%$ por lo que son capaces de recrear y representar imágenes en su mentes, sin embargo la menor concentración se encuentra en la Inteligencia Interpersonal con el $5 \%$ de la población por lo que es posible establecer que los niños no pueden controlar sus emociones ni poseen autocontrol. 


\section{CONCLUSIONES}

La escuela tradicional da importancia al aspecto académico y especialmente a limitadas áreas, el proceso de enseñanza se imparte de forma mecánica, memorista, en la cual el profesor muestra una imagen autoritaria, pero gracias a la constante evolución de la sociedad, la educación se ha visto en la necesidad de mejorar la calidad educativa, la misma que debe ser obligatoriamente innovadora, creativa y capas de fortalecer todas las áreas intelectuales del niño, en donde el docente aparece como orientador, con la capacidad de satisfacer las necesidades de los estudiantes, la teoría de las inteligencias múltiples presenta una comprensión más amplia del ser humano y el respeto a las diversas formas que tiene de manifestarse dentro de un contexto social.

Las inteligencias múltiples afectan la forma que tiene una persona de aprender, es por ello que se las debe tomar en cuanto al momento de planificar una clase procurando fomentar el desarrollo de la inteligencia presente en mayor cuantía en los niños, sin embargo si los docentes desean lograr el máximo alcance del potencial y el involucramiento del estudiante con su propio aprendizaje, deben desarrollar todas la habilidades y destrezas presentes en el educando, esto con la generación de espacios ricos para el aprendizaje y con la aplicación de mejores estrategias didácticas.

\section{REFERENCIAS BIBLIOGRÁFICAS}

ACRBIO, (2015). Imágenes educativas. Obtenido de Inteligencias Múltiples VS Sistema Educativo Tradicional: Documento Digital Disponible en: https://www.imageneseducativas.com/ inteligencias-multiples-vs-sistemaeducativo-tradicional/
Arcken, H. V. (2012). PEDAGOGÍA DOCENTE: Documento Digital Disponible en: https://pedagogiadocente.wordpress. com/modelos-pedagogicos/la-escuelatradicional/

Castro, M. (1939). Estudio crítico de las ideas pedagógicas de John Dewey. Habana: Ninon.

CEPES, (2000). Tendencias pedagógicas en la realidad educativa actual. Tarija : Universitaria. Obtenido de https://www. mutuamotera.org/gn/web/documentos/ contenidos/libro_de_tendencias_ docentes.pdf

Céspedes, A. (2019). ISEP. Instituto Superior de Estudios Psicológicos. Obtenido de https://www.isep.es/actualidadeducacion/inteligencia-primera-infancia/

Guillén, J. C. (2013). Escuela con cerebro. Documento Digital Disponible en: https://escuelaconcerebro.wordpress. com/2013/05/05/inteligencias-multiplesen-el-aula/

Gardner, H. (2016). Estructuras de la mente. La teoría de las inteligencias múltiples. Nueva york: fondo de cultura económica, pág.4

Guzmán, B., \& Castro, S. (2005). Las inteligencias multiples en el aula de clases. Revista de Investigación(58), pág.177-202

González, C. (2014). Las Inteligencias Múltiples en el aula de Educación Infantil. Repositorio Universidad de Zaragoza, pág.5-6 
Ordoñez-Islas, Y. I. (2006). Fomento de las inteligencias múltiples en preescolar por medio de la estrategia del cuento. Trabajo de obtención de grado, Maestría en Educación y Procesos Cognoscitivos. Tlaquepaque, Jalisco: ITESO, pág.18

Antunes, C. A. (2006). Estimular las Inteligencias Múltiples. qué son, cómo se manifiestan, cómo funcionan. Madrid: NARCEA, S.A. pag 10

Escalonilla, T. (2020). El Mundo. Obtenido de https://saposyprincesas.elmundo.es/ consejos/psicologia-infantil/metodoglenn-doman/

Pérez, L. \& Murzi, M. (2012). Destrezas $y$ habilidades como condiciones necesarias para el desarrollo de las actividades de campo. Revista Digital de Historia de la Educación. № 15, pág. 230.

García, M. T. (2009). La dimensión comunicativa de las inteligencias múltiple. CIC. Cuadernos de Información y Comunicación. Red de Revistas Científicas de América Latina, el Caribe, España y Portugal. Vol. 14, pág. 145

Sixto, S. \& Márquez, J. L. (2017). Tendencias teóricas en la conceptualización de las habilidades: Aplicación en la didáctica de la Oftalmología. Rev. Ciencias Médicas de Pinar del Río. Vol. 21, № 3, pág. 441
Ramírez, M. F. (2013). Desarrollo de las inteligencias múltiples para fortalecer las habilidades y destrezas cognitivas de los niños y niñas de primer año básico del centro de educación general básica $n^{\circ} 4$ "Once de Diciembre" del cantón la Libertad, Provincia de Santa Elena, durante el período lectivo 20122013. Repositorio Universidad Estatal Península de Santa Elena, pág. 62-83

Sánchez, L. I. (2015). La teoría de las inteligencias múltiples en la educación. Repositorio de la Universidad Mexicana, pág. 6

Hernández, R., Fernández, C. \& Baptista, P. (2003). Metodología de la investigación. México: McGraw-Hill. 